\title{
A pilot study on post-thawing quality of Iberian red deer spermatozoa (epididymal and electroejaculated) depending on glycerol concentration and extender osmolality
}

\author{
Felipe Martínez-Pastor ${ }^{a}$, Félix Martínez ${ }^{a}$, Vanesa García-Macías ${ }^{\text {a }}$, \\ Milagros C. Esteso ${ }^{\mathrm{c}, \mathrm{d}}$, Enrique Anel ${ }^{\mathrm{a}}$, Mara R. Fernández-Santos ${ }^{\mathrm{c}, \mathrm{d}}$, \\ Ana J. Soler ${ }^{\mathrm{c}}$, Paulino de Paz ${ }^{\mathrm{b}}$, Julián Garde ${ }^{\mathrm{c}, \mathrm{d}}$, Luis Anel ${ }^{\mathrm{a}, *}$ \\ ${ }^{a}$ Animal Reproduction and Obstetrics, University of León, 24071 León, Spain \\ ${ }^{\mathrm{b}}$ Cell Biology and Anatomy, Animal Reproduction and Obstetrics, University of León, 24071 León, Spain \\ ${ }^{\mathrm{c}}$ Grupo de Biología de la Reproducción, Instituto de Investigación en Recursos Cinegticos (IREC), \\ UCLM-CSIC-JCCM, 02071 Albacete, Spain \\ ${ }^{\mathrm{d}}$ Instituto de Desarrollo Regional (IDR), Sección de Recursos Cinegéticos y Ganaderos UCLM, 02071 Albacete, Spain
}

Received 24 October 2005; received in revised form 15 March 2006; accepted 17 March 2006

\begin{abstract}
The optimization of cryopreservation extenders is a fundamental issue for adequately performing germplasm banking on wild species. We have tested two glycerol concentrations (4 and 8\%), and three extender osmolalities $(320,380$ and $430 \mathrm{mOsm} / \mathrm{kg}$; before adding cryoprotectants), for cryopreservation of epididymal and ejaculated sperm samples from Iberian red deer. All the extenders were based on Tes-Tris and fructose (for osmolality adjustment), and complemented with $20 \%$ egg yolk. Epididymal and ejaculated sperm samples were obtained from the cauda epididymis (post-mortem) and using electroejaculation, respectively. Samples were diluted 1:1 with each extender and equilibrated for $2 \mathrm{~h}$ at $5{ }^{\circ} \mathrm{C}$. Then, they were diluted down to $100 \times 10^{6} \mathrm{sperm} / \mathrm{mL}$ and frozen at $-20^{\circ} \mathrm{C} / \mathrm{min}$. Post-thawed samples were assessed for motility (CASA), HOS test, proportion of swollen (osmotically challenged) cells in the untreated sample, viability and acrosomal status. For epididymal samples, $8 \%$ glycerol rendered a slightly higher proportion of intact acrosomes on viable spermatozoa than 4\%; regarding extender osmolality, 380 and $430 \mathrm{mOsm} / \mathrm{kg}$ rendered higher motility results, and the $430 \mathrm{mOsm} / \mathrm{kg}$ yielded the lowest proportion of swollen spermatozoa. For ejaculated samples, $4 \%$ glycerol yielded more viable spermatozoa than $8 \%$; for extender osmolality, $320 \mathrm{mOsm} / \mathrm{kg}$ rendered the highest percentages of progressively motile and viable spermatozoa, although $380 \mathrm{mOsm} / \mathrm{kg}$ extender was not significantly different. These results show that sample source influence extender suitability, and that extenders should be isoosmotic or rather slightly hyperosmotic. Future studies should test multiple glycerol concentrations and extender osmolalities in order to adjust them to these kinds of sample.
\end{abstract}

(C) 2006 Published by Elsevier Inc.

Keywords: Sperm cryopreservation; Epididymis; Electroejaculation; Extender; Red deer

* Corresponding author at: Biología Celular y Anatomía, Facultad de Biología y CC. AA., Campus de Vegazana, Universidad de León, 24071 León, Spain. Tel.: +34 987291 430; fax: +34 987295203.

E-mail address: dbcfmp@unileon.es (L. Anel).

\section{Introduction}

The composition of semen extenders is well known to affect the outcome of spermatozoa cryopreservation [1]. Not only cryoprotectants, but also sugars, buffer systems and other additives interact during the freezing- 
thawing process, often in a very specific manner, thus a lot of formulations have been proposed for different species [2,3]. In the case of wild species, available extenders are frequently adapted from others from domestic species, with little or no modifications. However, due to the importance of species differences, it is important to study each case in order to refine these extenders, to obtain optimal results.

There are few comparative studies on extenders for cervid semen [4,5], despite of the interest of these species, not only because of their ecological value, but also as trophies and farm animals [6], especially in the case of the red deer (Cervus elaphus). The creation of germplasm banks would greatly improve their management, both for economical and conservationist purposes, and many successful experiences on semen cryopreservation and insemination have been reported [7-13], using extenders usually adapted from formulations for bull or ram semen, but more detailed studies are scarce.

Among cryoprotectants, glycerol is considered as the most effective for red deer, such as in other ruminants. Nevertheless, an optimal concentration has not been defined yet, since comparative studies were generally carried out using extenders varying on many parameters (buffer, sugars, glycerol concentration, etc), thus making difficult to take decisions about the most adequate glycerol concentration. Reported concentrations ranged from 5 to $10 \%$ [7-13], but results seem to depend rather on other components or on the followed protocols than on glycerol concentration. Thus, extenders with the same glycerol concentration have frequently yielded different results, and vice versa [5].

Other important aspect in extender composition is the osmolality due to its impermeant components. During freezing and thawing, spermatozoa undergo dehydration and rehydration, which have an important impact in sperm endurance to cryopreservation, because dehydration decreases the risk of intracellular ice crystal formation (although excessive dehydration is detrimental too) [14-16]. Thus, adjusting the osmolality of the extender is of great importance, since it would influence the amount of intracellular water during the different steps of cryopreservation, which has been an issue subjected to study on many papers [17-22]. In general, it has been found that spermatozoa from different species respond differently to changes in the osmolality of the surrounding media, and that the osmolality of the extender is an important factor for the outcome of the cryopreservation [21]. However, these studies have been limited to several domestic species and human spermatozoa, and, taking into account the variability found, it is not possible to merely extrapolate these results to other species.

Currently, there are few studies dealing with the cryopreservation and utilization of epididymal samples (obtained post-mortem) from red deer [10,13,23-25], despite of the value of these kinds of samples for germplasm banking of wild animals [26]. Although the use of extenders adapted from other ruminants have rendered good results, it would be highly desirable to optimize them in order to attain a good availability of specific extenders.

In this study, we have tested the effect of two glycerol concentrations and three extender osmolalities (previously to cryoprotectant addition) in the postthawing quality of red deer spermatozoa, obtained by electroejaculation and by post-mortem recovery. This work must be considered within a more general plan to develop optimized extenders for cryopreservation of sperm from wild ruminants, in order to utilize them in the setting-up of germplasm banks. Besides to this practical approach, we are carrying out experiments to study basic aspects of sperm cryobiology, which may be helpful to understand and develop efficient cryopreservation protocols, not only for this species, but also for others.

\section{Materials and methods}

\subsection{Animals}

Epididymal samples were collected from 38 Iberian red deer (C. elaphus hispanicus, Helzheimer 1909) harvested in the game reserves of Ancares, Mampodre and Picos de Europa (León, Spain) and in several private hunting reserves of the region of Cáceres (Spain). All the animals were adults and lived in a freeranging regime. Harvest plans followed Spanish Harvest Regulation, Law 4/96 of Castilla y León and Law 19/01 of Extremadura, which conforms to European Union Regulation. Furthermore, species and number of individuals that can be hunted, as well as the exact periods of the year when hunting can take place, are reviewed each year by the Annual Hunting Regulation of the respective regions.

Electroejaculation samples were obtained from 9 mature Iberian red deer stags. Animals (2-5 year old; $100-150 \mathrm{~kg}$ ) were housed in a half-freedom regime at the University of Castilla-La Mancha (ETSIA, Albacete, Spain), maintained under natural daylength conditions at a latitude of $38^{\circ} 57^{\prime} \mathrm{N}$. During the experiment they lived in an artificial meadow of $6500 \mathrm{~m}^{2}$ composed of Festuca arundinacea (52.4\%), 
Dactylis glomerata (28.6\%), Medicago sativa (14.3\%) and Trifolium repens (4.8\%). Fodder was based on barley, alfalfa and oats, and animals had ad libitum access to cereal straw and water. Animal handling was performed in accordance with the Spanish Animal Protection Regulation, RD223/1998, which conforms to European Union Regulation 86/609 and adheres to guidelines established in the Guide for Care and Use of Laboratory Animals as adopted and promulgated by the American Society of Andrology.

In both cases, samples were collected during the breeding season (autumn).

\subsection{Post-mortem sperm recovery}

Scrotum, including testicles and epididymes, was removed from the carcass and refrigerated down to $5{ }^{\circ} \mathrm{C}$ as soon as possible. Date and time of death, collection and refrigeration were noted and attached to the corresponding sample. Refrigerated genitalia were sent to our laboratory at the Veterinary Clinic Hospital of the University of León (Spain). Post-mortem time ranged between 10 and $20 \mathrm{~h}$, which we considered acceptable for maintaining sperm quality [27].

Sample manipulation was carried out in a walk-in fridge $\left(5^{\circ} \mathrm{C}\right)$. Testicles with epididymes and vas deferens attached were isolated from the scrotum and other tissues. Epididymes were dissected free from the testicles, and cleaned of connective tissue. To avoid blood contamination, superficial blood vessels were previously cut and their contents wiped out. Spermatozoa were collected making several incisions on the cauda epididymis with a surgical blade, and taking the liquid emerging from the cut tubules with the aid of the blade. Osmolality of each sample was measured using a cryoscopic osmometer (Osmomat-030, Gonotec ${ }^{\mathrm{TM}}$; Berlin).

\subsection{Electroejaculation procedure}

Previously to electroejaculation, stags were restrained and anaesthetised with intravenous injection of xylacine and ketamine (Rompun ${ }^{\circledR} 2 \%$ and Imalgene $1000^{\circledR}$ ). Rectum was cleaned from faeces and the prepucial area was shaved and washed with physiological saline serum. Electroejaculation was carried out using a 3-electrode probe $(250 \mathrm{~mm}$ $\times 30 \mathrm{~mm}$ ) connected to a power source which allowed voltage and amperage control. Ejaculation occurred at average values of $4.5 \mathrm{~V}$ and $90 \mathrm{~mA}$ (average time to ejaculation: $3 \min 44 \mathrm{~s}$ ). Anesthesia was reverted with yohimbine $0.9 \%$. Osmolality of ejaculates was measured in the same manner than for post-mortem samples.

\subsection{Preparation of the extenders}

All chemicals were acquired from Sigma (Madrid, Spain). The extenders were based in a Tes-Tris buffering system, using fructose for adjusting osmolality and complemented with egg yolk and glycerol as cryoprotectants [28]. In order to prevent variations due to egg yolk, it was obtained from fresh hen eggs in aseptic conditions, and all the yolks were pooled. All the extenders used for each experiment were prepared the same day and using the same egg yolk pool.

For the comparison of glycerol concentrations on epididymal samples, two extenders were prepared as follows: a buffered solution (Tes $231.1 \mathrm{mmol} / \mathrm{L}$, Tris $77.1 \mathrm{mmol} / \mathrm{L}$ and fructose $121.9 \mathrm{mmol} / \mathrm{L}$ in milli-Q water; $\mathrm{pH} 7.2$ and $430 \mathrm{mOsm} / \mathrm{kg}$ ) was prepared and double-filtered through a cellulose acetate membrane $(0.22 \mu \mathrm{m}$ pore $)$; then, it was complemented with $15 \%$ egg yolk and centrifugated $(3000 \times g, 30 \mathrm{~min})$, discarding the sediment. Finally, we added 4 or $8 \%$ glycerol (final concentration), depending on the variant, which were called G4 and G8, respectively. For the experiment on electroejaculated samples, the same procedure was followed, but we added $16.9 \mathrm{mmol} / \mathrm{L}$ of fructose, so the osmolality of the solution before adding glycerol and egg yolk was $320 \mathrm{mOsm} / \mathrm{kg}$.

The extenders used in the study of extender osmolalities were prepared similarly. In this case, fructose concentration was adjusted to obtain an osmolality (before adding egg yolk and glycerol) of $320 \mathrm{mOsm} / \mathrm{kg} \quad(16.9 \mathrm{mmol} / \mathrm{L}), \quad 380 \mathrm{mOsm} / \mathrm{kg} \quad(74.7$ $\mathrm{mmol} / \mathrm{L})$ or $430 \mathrm{mOsm} / \mathrm{kg}(121.9 \mathrm{mmol} / \mathrm{L})$. Then, the solution was complemented with egg yolk (15\%) and glycerol, as described above. Glycerol concentration was $4 \%$ for electroejaculated samples and $8 \%$ for epididymal samples. The three extenders were called E320, E380 and E430, accordingly to the adjusted osmolalities.

\subsection{Cryopreservation protocol}

Samples were diluted $1: 1$ in the corresponding extender. This dilution was carried out at $5{ }^{\circ} \mathrm{C}$ for epididymal samples (the same temperature they arrived at our laboratory) and at ambient temperature for electroejaculated samples. The tubes containing the later were then put in glasses containing $100 \mathrm{~mL}$ of water at ambient temperature and transferred to $5{ }^{\circ} \mathrm{C}$, so temperature decreased smoothly. After resting $2 \mathrm{~h}$ at 
$5{ }^{\circ} \mathrm{C}$, the sample was further diluted with the same extender down to $100 \times 10^{6} \mathrm{sperm} / \mathrm{mL}$ and packed in $0.25 \mathrm{~mL}$ French straws. Freezing was carried out using a programmable biofreezer (Planner MRII $^{\mathbb{R}}$ ), at $-20{ }^{\circ} \mathrm{C} / \mathrm{min}$ down to $-100{ }^{\circ} \mathrm{C}$, and then transferred to liquid nitrogen containers. Thawing was performed by dropping the straws in water at $65^{\circ} \mathrm{C}$ for $6 \mathrm{~s}$.

\subsection{Motility analysis}

Thawed samples were diluted down to $10-20 \times$ $10^{6}$ spermatozoa $/ \mathrm{mL}$ in PBS (pH 7.5, $320 \mathrm{mOsm} / \mathrm{kg}$ ). A $5 \mu \mathrm{L}$ drop was examined with a phase contrast microscope (Nikon Labophot-2; negative contrast optics), on a warming stage at $37^{\circ} \mathrm{C}$. We used a CASA system to analyze motility (Motility Analyzer v. 7.4 G, Hamilton-Thorne Research ${ }^{\mathrm{TM}}$ ), collecting the following parameters for further analysis: total motility (\%; $\mathrm{TM})$, progressive motility (\%; PM), average path velocity $(\mu \mathrm{m} / \mathrm{s}$; VAP) and linearity $(\% ; \mathrm{LIN})$. Detailed explanation of these descriptors of sperm movement has been provided elsewhere [29]. At least 5 fields and 200 cells were recorded at $\times 200$, using an image acquisition rate of 25 frames/s and an acquisition time of $0.8 \mathrm{~s}$. Progressive motility was defined as the percentage of total spermatozoa with VAP $>25 \mu \mathrm{m} / \mathrm{s}$ and straightness (STR) $>80 \%$.

\subsection{HOS test}

The functional integrity of the sperm plasma membrane was evaluated using the hypoosmotic swelling test (HOS test). Five microliters of sample were diluted in $500 \mu \mathrm{L}$ of a hypoosmotic sodium citrate solution $(100 \mathrm{mOsm} / \mathrm{kg})$. After $18 \mathrm{~min}$ at room temperature, samples were fixed with a drop of glutaraldehyde solution. Responsiveness to the test was determined by counting 100 cells with a phase-contrast microscope $(\times 400)$. The percentage of positive cells (those with a swollen flagelle) was recorded for each sample [30].

\subsection{Assessment of osmotically challenged spermatozoa}

We determined the percentage of spermatozoa with swollen tails (osmotically challenged) in the untreated samples $(5 \mu \mathrm{L}$ of thawed sample fixated in $500 \mu \mathrm{L}$ of the glutaraldehyde solution), in order to assess if there were spermatozoa with signs of osmotic stress in the samples (OSM).

\subsection{Evaluation of sperm viability and acrosomal status}

Samples (pre-freezing and post-thawed) were diluted in buffered media (1:100, same composition that the one used for motility analysis), and stained with propidium iodide (PI; $25 \mu \mathrm{g} / \mathrm{L}$ ) and PNA lectin conjugated with FITC $(1 \mu \mathrm{g} / \mathrm{mL})$. After $10 \mathrm{~min}$, the samples were analyzed using a FACSCalibur flow cytometer (Becton Dickinson, Franklin Lakes, NJ). We used a $15 \mathrm{~mW}$ argon-laser that provided an excitation wavelength of $488 \mathrm{~nm}$, using the FL3 photodetector channel to read the red emission light of PI (650 long pass filter), and the FL1 photodetector channel to read the green emission light of FITC (530/30 band pass filter). At least 10,000 events (spermatozoa detected, after discarding debris) were acquired. The fluorescent technique allows to distinguish among four sperm populations: red (nonviable, acrosome intact), red-green (non-viable, acrosome damaged), green (viable, acrosome damaged) and non-stained (viable; acrosome intact) spermatozoa [31]. For data analysis, we used the percentage of viable spermatozoa (green + non-stained cells; VIAB) and the proportion of viable spermatozoa with intact acrosomes respect to the total percentage of viable spermatozoa (non-stained/viable $\times 100 ;$ ACR).

\subsection{Statistical analysis}

Statistical analysis were carried out using the SAS/ STAT $^{\mathrm{TM}}$ program (SAS Inc., Cary, NC). Previously, we transformed our data using arc sine (percentages) or decimal logarithm. Treatment comparison (glycerol concentration or extender osmolality) was performed by ANOVA, with sample and treatment (glycerol concentration or extender osmolality) as factors of variation. Treatments (whenever this factor was significant) were compared using Tukey-Kramer multiple comparison for adjusted means.

\section{Results}

\subsection{Epididymal samples}

Of the 38 post-mortem samples, 12 were used for comparing glycerol concentrations and 26 for the extender osmolality experiment. Osmolality of epididymal samples was $387 \pm 27 \mathrm{mOsm} / \mathrm{kg}$ (mean \pm S.D.), which is in agreement with a previous study on red deer epididymal samples [27].

Almost no differences were detected among samples frozen using 4 or $8 \%$ glycerol. As Table 1 shows, neither 
Table 1

Post-thawing results for the two glycerol concentrations (G4: 4\%; G8: $8 \%$ ) assayed on epididymal sample (adjusted means and S.E.M.)

\begin{tabular}{lcc}
\hline Parameter & G4 & G8 \\
\hline TM $(\%)$ & $47.08 \pm 7.34$ & $48.25 \pm 9.66$ \\
PM $(\%)$ & $17.50 \pm 3.75$ & $16.83 \pm 4.38$ \\
VAP $(\mu \mathrm{m} / \mathrm{s})$ & $45.58 \pm 1.74$ & $43.30 \pm 2.05$ \\
LIN $(\%)$ & $52.17 \pm 1.30$ & $48.67 \pm 1.54$ \\
HOS test $(\%)$ & $54.55 \pm 1.80$ & $55.91 \pm 1.80$ \\
OSM $(\%)$ & $7.44 \pm 0.63$ & $6.33 \pm 0.63$ \\
VIAB $(\%)$ & $56.30 \pm 2.50$ & $55.00 \pm 3.15$ \\
ACR $(\%)$ & $93.14 \pm 1.57 \mathrm{a}$ & $95.56 \pm 1.69 \mathrm{~b}$ \\
\hline
\end{tabular}

TM: total motility; PM: progressive motility; OSM: spermatozoa with a swollen tail; VIAB: sperm viability; ACR: \% of acrosome-intact sperm within VIAB. Different letters indicate that columns differ $P<0.05$. motility nor viability were significantly affected by this factor. Only acrosomal status seemed to be better preserved when the $8 \%$ concentration was used, although the difference was minimal.

The comparison between the three osmolalities of the extenders showed that total motility of post-thawed sperm was significantly lower when using E320 (Table 2). Besides, there was a decreasing proportion of spermatozoa with swollen tails (OSM, osmotically stressed) with increasing extender osmolality. Results for other parameters were very similar in the three extenders.

\subsection{Electroejaculated samples}

A total of 32 electroejaculations were carried out, using 8 samples for comparing glycerol concentrations and 24 for the extender osmolality experiment.

Table 2

Post-thawing results for the three extender osmolalities (E320: $320 \mathrm{mOsm} / \mathrm{kg}$; E380: $380 \mathrm{mOsm} / \mathrm{kg}$; E430: $430 \mathrm{mOsm} / \mathrm{kg}$ ) assayed on epididymal samples (adjusted means and S.E.M.)

\begin{tabular}{llcl}
\hline Parameter & E320 & E380 & E430 \\
\hline TM $(\%)$ & $41.90 \pm 2.20 \mathrm{a}$ & $50.47 \pm 2.02 \mathrm{~b}$ & $50.68 \pm 2.13 \mathrm{~b}$ \\
PM $(\%)$ & $13.35 \pm 1.07$ & $16.48 \pm 0.98$ & $16.77 \pm 1.04$ \\
VAP $(\mu \mathrm{m} / \mathrm{s})$ & $45.21 \pm 1.26$ & $43.08 \pm 1.17$ & $44.09 \pm 1.18$ \\
LIN $(\%)$ & $49.33 \pm 0.96$ & $48.03 \pm 0.89$ & $48.27 \pm 0.90$ \\
HOS test $(\%)$ & $54.09 \pm 1.26$ & $52.00 \pm 1.21$ & $52.09 \pm 1.25$ \\
OSM (\%) & $10.57 \pm 0.42 \mathrm{a}$ & $9.34 \pm 0.30 \mathrm{~b}$ & $7.21 \pm 0.42 \mathrm{c}$ \\
VIAB (\%) & $51.92 \pm 1.47$ & $52.92 \pm 1.41$ & $53.18 \pm 1.47$ \\
ACR (\%) & $96.66 \pm 0.56$ & $98.09 \pm 0.53$ & $98.57 \pm 0.56$ \\
\hline
\end{tabular}

TM: total motility; PM: progressive motility; OSM: spermatozoa with a swollen tail; VIAB: sperm viability; ACR: $\%$ of acrosome-intact sperm within VIAB. Different letters indicate that columns differ $P<0.05$.
Table 3

Post-thawing results for the two glycerol concentrations (G4: 4\%; G8: $8 \%$ ) assayed on electroejaculated samples (adjusted means and S.E.M.)

\begin{tabular}{lcc}
\hline Parameter & G4 & G8 \\
\hline TM $(\%)$ & $63.75 \pm 5.81$ & $52.63 \pm 5.81$ \\
PM $(\%)$ & $42.50 \pm 3.19$ & $36.00 \pm 3.19$ \\
VAP $(\mu \mathrm{m} / \mathrm{s})$ & $60.36 \pm 2.07$ & $53.50 \pm 1.82$ \\
LIN $(\%)$ & $76.41 \pm 6.46$ & $65.13 \pm 5.69$ \\
HOS test $(\%)$ & $27.38 \pm 1.72$ & $26.38 \pm 1.72$ \\
OSM $(\%)$ & $0.38 \pm 0.08$ & $0.25 \pm 0.08$ \\
VIAB $(\%)$ & $45.13 \pm 1.84 \mathrm{a}$ & $38.25 \pm 1.83 \mathrm{~b}$ \\
ACR $(\%)$ & $99.06 \pm 0.33$ & $99.25 \pm 0.33$ \\
\hline
\end{tabular}

TM: total motility; PM: progressive motility; OSM: spermatozoa with a swollen tail; VIAB: sperm viability; ACR: \% of acrosome-intact sperm within VIAB. Different letters indicate that columns differ $P<0.05$.

Osmolality of electroejaculated samples was $336 \pm 44 \mathrm{mOsm} / \mathrm{kg}$ (mean \pm S.D.).

As in the case of the epididymal samples, there was little difference between the results obtained using 4 or $8 \%$ glycerol for cryopreservation (Table 3 ). However, in this case $4 \%$ glycerol rendered higher mean results, but significance was only reached for viability.

Table 4 shows results for the extender osmolality comparison. In this case, E320 rendered significantly higher results for progressive motility and sperm viability than E430. There were no significant differences among E380, which yielded intermediate values, and the other two extenders.

\section{Discussion}

In this study, we have noticed some interesting differences regarding extender suitability for red deer
Table 4

Post-thawing results for the three extender osmolalities (E320: $320 \mathrm{mOsm} / \mathrm{kg}$; E380: $380 \mathrm{mOsm} / \mathrm{kg}$; E430: $430 \mathrm{mOsm} / \mathrm{kg}$ ) assayed on electroejaculated samples (adjusted means and S.E.M.)

\begin{tabular}{llll}
\hline Parameter & E320 & E380 & E430 \\
\hline TM (\%) & $47.96 \pm 2.39$ & $44.77 \pm 2.39$ & $42.24 \pm 2.48$ \\
PM $(\%)$ & $31.19 \pm 1.67$ a & $29.52 \pm 1.67 \mathrm{a}, \mathrm{b}$ & $26.16 \pm 1.73 \mathrm{~b}$ \\
VAP $(\mu \mathrm{m} / \mathrm{s})$ & $59.92 \pm 1.94$ & $60.50 \pm 1.97$ & $57.89 \pm 2.05$ \\
LIN (\%) & $56.77 \pm 5.33$ & $64.16 \pm 5.39$ & $70.64 \pm 5.61$ \\
HOS test (\%) & $22.57 \pm 0.74$ & $21.57 \pm 0.74$ & $21.32 \pm 0.74$ \\
OSM (\%) & $0.54 \pm 0.17$ & $0.33 \pm 0.17$ & $0.29 \pm 0.16$ \\
VIAB (\%) & $49.15 \pm 1.46 \mathrm{a}$ & $44.15 \pm 1.46 \mathrm{a}, \mathrm{b}$ & $42.87 \pm 1.46 \mathrm{~b}$ \\
ACR (\%) & $98.83 \pm 0.49$ & $98.80 \pm 0.49$ & $97.65 \pm 0.49$
\end{tabular}

TM: total motility; PM: progressive motility; OSM: spermatozoa with a swollen tail; VIAB: sperm viability; ACR: \% of acrosome-intact sperm within VIAB. Different letters indicate that columns differ $P<0.05$. 
sperm cryopreservation, depending on sample source (ejaculate or epididymis). We took into account the osmolality of the epididymal and ejaculated samples that we had obtained in previous studies $[27,32,33]$ for the design of this experiment. Therefore, we carried out firstly the comparison of glycerol concentrations using for each kind of sample the extender we considered more adequate (E320 for electroejaculated samples and E430 for epididymal samples). Once we had an estimation of the most suitable glycerol concentration (4\% for electroejaculated samples and $8 \%$ for epididymal samples), we prepared the extenders for the comparison of extender osmolalities, using the corresponding glycerol concentration.

The few differences found in the comparison of the two glycerol concentrations indicated that red deer spermatozoa have a broad margin of tolerance to glycerol. These results are in accordance to published data on red deer semen, both from epididymal and ejaculated sources, which report successful cryopreservation using a wide range of glycerol concentrations (from 4 to 10\%) [7,10,12,13,25]. Recently, Cheng et al. [5], working with electroejaculated semen from Cervus nippon and Cervus unicolor, tested five different diluents with glycerol concentrations ranging 5-8\%, and their results suggested that the efficacy of each extender was rather due to the presence of specific components and their interactions, than to glycerol concentration alone.

In this study we have analyzed two extenders varying solely in glycerol concentration, in order to isolate this factor. It seems that, effectively, epididymal spermatozoa from red deer can be cryopreserved almost equally in 4 and $8 \%$ glycerol, the later being preferred attending to its slightly better acrosomal protection. However, considering electroejaculated samples, $4 \%$ would be the recommended choice, since it yielded higher sperm viability. Taking into account the importance of this parameter, low glycerol concentrations may be adequate in formulations similar to ours. Nevertheless, as the study of Cheng et al. [5] suggests, glycerol effects may be modulated by other components of the extender, making necessary test not only a wider range of glycerol concentrations, but also its effect when used in different kind of extenders.

The other factor we studied, extender osmolality due to non-permeant components, is of great importance on sperm cryopreservation. For epididymal samples, extender E320 rendered the lowest post-thawing motility (TM) and the higher proportion of spermatozoa with a swollen tail (because of osmotic stress). This osmolality is much lower than the usual values for epididymal samples $(387 \mathrm{mOsm} / \mathrm{kg}$ on average in this study). On the other hand, E380 and E430 yielded significantly higher total motility, and E430 yielded the lowest percentage of swollen spermatozoa. Therefore, a high extender osmolality would be preferred when cryopreserving epididymal samples, even higher that the osmolality of the samples. Regarding the proportion of swollen spermatozoa, we have to consider that the female genital tract comprises a series of challenges for the spermatozoa, the first one consisting in the osmotic changes undergone by spermatozoa when depositing the thawed sample in the vagina or uterus [34]. Therefore, extenders that submit spermatozoa to unnecessary osmotic stress during the cryopreservation process should be avoided, since that stress may eventually reflect on a decreased fertilizing ability.

On the other hand, considering ejaculated samples, our results indicated that E320 would be the most adequate extender of the three tested. This result is logical considering the average osmolality of our electroejaculated samples $(336 \mathrm{mOsm} / \mathrm{kg})$. This would have made E430 too hyperosmotic for our samples, reflecting on the significantly lower results for progressive motility and viability when comparing with E320.

These results show that extender composition should be modified accordingly to the source of the sample, either ejaculated or epididymary (higher osmolality), and that better results might be achieved using an extender with an osmolality similar to that expected of the sample. Nevertheless, the good results obtained with E430 on epididymal samples and the acceptable ones with E380 on electroejaculated samples suggest that moderately hyperosmotic extenders might render even better results than isoosmotic ones, as other authors have proposed. Indeed, Liu et al. [21] found that increasing osmolality protected better bull spermatozoa during cryopreservation, provided that a rapid cooling rate was used. The explanation given by these authors was that a higher osmolality allowed a faster dehydration compatible with the cooling rate. Tested media ranged from 220 to $455 \mathrm{mOsm} / \mathrm{kg}$, and, in general, good results were obtained for $260-380 \mathrm{mOsm} / \mathrm{kg}$ (depending on extender composition). Besides, Aisen et al. [17], working with ram semen, found that increasing extender osmolality improved cryopreservation results, but only to certain limit (up to a $100 \mathrm{mOsm} / \mathrm{kg}$ increment), and that it reflected into better lambing results.

We have observed a decreasing trend on some quality parameters of electroejaculated semen with increasing extender osmolality. However, the fact that 
there were no significant differences between E320 and E380, and the findings of those authors, support the hypothesis that intermediate osmolalities may be more suitable than isoosmotic extenders. Besides, epididymal samples could be more resilient to hyperosmotic extenders and to the subsequent dehydration during the cryopreservation process, thus benefiting from these extenders without undergoing detrimental effects.

The findings of this study have a practical application considering the lack of comparative studies on extenders for cryopreservation of red deer semen. We have found that cryopreservation of epididymal and ejaculated sperm would require of different glycerol concentrations ( 8 and $4 \%$, respectively). However, differences between the two concentrations were low, and at least epididymal samples seemed to have a high tolerance to glycerol. Considering osmolality of the extender, our results indicate that it is necessary to take into account the osmolality of the sample and its source, in order to design the extender accordingly. Isoosmotic extenders would render good results, however moderately hyperosmotic ones may be a better choice for cryopreservation. Considering the importance of extender design on the success of sperm banking, future studies should include testing of multiple glycerol concentrations and of hyperosmotic extenders for cryopreservation of these samples, adjusting these parameters according to sample source and characteristics.

\section{Acknowledgements}

This study has been supported in part by Junta de Castilla y León (AB29) and Junta de Castilla-La Mancha (PREG-01-0006). The authors thank Juan José Martnez, César Gómez, Juan Carlos Peral, the Territorial Service of Environmental Affairs of León, and the gamekeepers of the hunting reserves of Picos de Europa, Mampodre and Ancares (León, Spain) for their collaboration in the collection of the samples used in this work; and Camino Guerra and Patri Martínez for her help in the processing of the samples.

\section{References}

[1] Yoshida M, Forsberg M, Greve T, Gustafsson H, Katila T, Kindahl H, et al. Conservation of sperms: current status and new trends. Anim Reprod Sci 2000;60/61:349-55.

[2] Salamon S, Maxwell WMC. Storage of ram semen. Anim Reprod Sci 2000;62:77-111.

[3] Watson PF, Holt WV. Cryobanking the Genetic Resource: Wildlife Conservation for the Future? London: Taylor and Francis; 2001.
[4] Asher G, Berg D, Evans G, Salamon S, Maxwell W. Storage of semen and artificial insemination in deer. Anim Reprod Sci 2000;62:195-211.

[5] Cheng FP, Wu JT, Chan JP, Wang JS, Fung HP, Colenbrander B, et al. The effect of different extenders on post-thaw sperm survival, acrosomal integrity and longevity in cryopreserved semen of Formosan Sika deer and Formosan Sambar deer. Theriogenology 2004;61:1605-16.

[6] Fletcher TJ. Farmed deer: new domestic animals defined by controlled breeding. Reprod Fertil Dev 2001;13:511-6.

[7] Asher GW, Monfort SL, Wemmer C. Comparative reproductive function in cervids: implications for management of farm and zoo populations. J Reprod Fertil Suppl 1999;54:143-56.

[8] Garde J, Garcia A, Ortiz N, Lopez A, Gallego L. Artificial insemination in Iberian deer (Cervus elaphus hispanicus) with frozen-thawed epididymal spermatozoa. In: Proceedings of the Fourth International Deer Biology Congress; 1998. p. $166-8$.

[9] Gordon I. Controlled reproduction in deer. In: Controlled reproduction in horses, deer and camelids, CAB International, Oxon, UK, vol. 4 of Controlled reproduction in farm animals. 1st ed., pp. $168-188$.

[10] Martinez-Pastor F, Garcia-Macias V, Alvarez M, Herraez P, Anel L, de Paz P. Sperm subpopulations in Iberian red deer epididymal sperm and their changes through the cryopreservation process. Biol Reprod 2005;72:316-27.

[11] Ortiz N, Garcia A, Montoro V, Gallego L, Garde J. Cryopreservation and maturation of epididymal deer spermatozoa. In: Proceedings of the First Congresso Iberico Reproducao Animal; 1997. p. 289-94.

[12] Soler AJ, Astore V, Sestelo A, Rivolta M, Jacome LN, Garde JJ. Effect of thawing procedure on cryosurvival of deer spermatozoa: work in progress. Theriogenology 2003;60:511-20.

[13] Zomborszky Z, Zubor T, Toth J, Horn P. Sperm collection from shot red deer stags (Cervus elaphus) and the utilisation of sperm frozen and subsequently thawed. Acta Vet Hung 1999;47:263-70.

[14] Agca Y, Critser JK. Cryopreservation of spermatozoa in assisted reproduction. Semin Reprod Med 2002;20:15-23.

[15] Hammerstedt RH, Graham JK, Nolan JP. Cryopreservation of mammalian sperm: what we ask them to survive. J Androl 1990;11:73-88.

[16] Watson PF. Recent developments and concepts in the cryopreservation of spermatozoa and the assessment of their postthawing function. Reprod Fertil Dev 1995;7:871-91.

[17] Aisen EG, Medina VH, Venturino A. Cryopreservation and postthawed fertility of ram semen frozen in different trehalose concentrations. Theriogenology 2002;57:1801-8.

[18] Curry MR, Watson PF. Osmotic effects on ram and human sperm membranes in relation to thawing injury. Cryobiology 1994; 31:39-46.

[19] Fiser PS, Ainsworth L, Langford GA. Effect of osmolality of skim-milk diluents and thawing rate on cryosurvival of ram spermatozoa. Cryobiology 1981;18:399-403.

[20] Iguer-ouada M, Verstegen JP. Long-term preservation of chilled canine semen: effect of commercial and laboratory prepared extenders. Theriogenology 2001;55:671-84.

[21] Liu Z, Foote R, Brockett C. Survival of bull sperm frozen at different rates in media varying in osmolarity. Cryobiology 1998;37:219-30.

[22] Liu Z, Foote RH. Bull sperm motility and membrane integrity in media varying in osmolality. J Dairy Sci 1998;81:1868-73. 
[23] Garde JJ, Ortiz N, Garcia AJ, Lopez A, Gallego L. Criopreservación postmortem de material espermático e inseminación artificial en el ciervo ibérico. Arch Zootec 1998;47:351-6.

[24] Hishinuma M, Suzuki K, Sekine J. Recovery and cryopreservation of Sika deer (Cervus nippon) spermatozoa from epididymides stored at $4{ }^{\circ} \mathrm{C}$. Theriogenology 2003;59:813-20.

[25] Soler AJ, Garcia AJ, Fernandez-Santos MR, Esteso MC, Garde JJ. Effects of thawing procedure on postthawed in vitro viability and in vivo fertility of red deer epididymal spermatozoa cryopreserved at $-196{ }^{\circ} \mathrm{C}$. J Androl 2003;24:746-56.

[26] Foote R. Fertilizing ability of epididymal sperm from dead animals. J Androl 2000;21:355.

[27] Martinez-Pastor F, Guerra C, Kaabi M, Diaz AR, Anel E, Herraez P, et al. Decay of sperm obtained from epididymes of wild ruminants depending on postmortem time. Theriogenology 2005;63:24-40.

[28] Anel L, de Paz P, Alvarez M, Chamorro CA, Boixo JC, Manso A, et al. Field and in vitro assay of three methods for freezing ram semen. Theriogenology 2003;60:1293-308.

[29] Mortimer D, Serres C, Mortimer ST, Jouannet P. Influence of image sampling frequency on the perceived movement characteristics of progressively motile human spermatozoa. Gamete Res 1988;20:313-27.
[30] Jeyendran RS, Van der Ven HH, Perez-Pelaez M, Crabo BG, Zaneveld LJ. Development of an assay to assess the functional integrity of the human sperm membrane and its relationship to other semen characteristics. J Reprod Fertil 1984;70:219-28.

[31] Brito LF, Barth AD, Bilodeau-Goeseels S, Panich PL, Kastelic JP. Comparison of methods to evaluate the plasmalemma of bovine sperm and their relationship with in vitro fertilization rate. Theriogenology 2003;60:1539-51.

[32] Martinez-Pastor F, Alvarez M, Martinez F, Garcia A, Anel E, Soler A, et al. Seminal parameters of Iberian red deer (Cervus elaphus hispanicus) and the effect of hybridation (hispanicus $\times$ scoticus) on its quality. In: Proceedings of the 15 th International Congress on Animal Reproduction, vol. 1; 2004.p. 219

[33] Martinez F, Martinez-Pastor F, Anel L, Soler A, Anel E, Garcia A, et al. Seminal characteristics of Iberian red deer (Cervus elaphus hispanicus) depending on casting time. In: Proceedings of the 15th International Congress on Animal Reproduction, vol. 1; 2004.p. 220.

[34] Wessel MT, Ball BA. Step-wise dilution for removal of glycero from fresh and cryopreserved equine spermatozoa. Anim Reprod Sci 2004;84:147-56. 